\title{
AL-BALAGHAH; \\ ANTARA PENGETAHUAN DAN DISIPLIN ILMU (PERSPEKTIF SEJARAH BAHASA DAN SASTRA ARAB)
}

\author{
M. Abdul Hamid
}

Dosen dan Sekretaris Jurusan Pendidikan Bahasa Arab,

Fakultas Humaniora dan Budaya, Universitas Islam Negeri (UIN) Malang.

Jalan Gajayana No. 50 Telepon (0341) 570872, Faksimile (0341) 570872 Malang 65144

\begin{abstract}
At first, the study of al balaghah was focused on the study of al ma'nani, that functions to remove lahn similar with nahwu. The history of al balaghah is divided into four stages, 1) marhalah al-nasy'ah (growth), (2) marhalah al-numuw (development), (3) marhalah al-izdizar (glory), and (4) marhalah al-dhubul (decline). In Jahiliyah era, the Arabs used al fashahah and al balaghah in their language. They were proud much on their language style in orang language, however the al-balaghah was not constructed as a field of knowledge yet. During Bani Ummaya era, there were many khitabaat, asy'ar and natsr contributing to the development albalaghah as a field of study. Furthermore, in Bani Abbasiyyah era, al balaghah as a field of study was well formed so that mustholahaat on the discussion of balaghah was defined and well ordered. In the following era, al balaghah declined without significant development.
\end{abstract}

Keywords

Al-Balaghah, History, Development of Arabic

\section{Pendahuluan}


Al-Balaghah bagi orang Arab sudah menjadi karakter dan sifat mereka bahkan sudah menjadi fitrah mereka, bukan saja bagi orang dewasanya, tetapi juga bagi semua kalangan dan golongan, mulai dari anak-anak sampai para perempuannya. Hal ini dapat kita buktikan melalui betapa banyak kata-kata bijak (hikam) dan pribahasa-pribahasa (matsal) yang mengandung al-balaghah yang tinggi.

Dalam sejarah sastra Arab, sudah sangat populer bahwa mereka mempunyai kegiatan rutin yang disebut sebagai aswaaq adabiyah (pasar sastra) dimana mereka saling mengekpresikan dan menunjukan karya sastra tinggi yang tidak diragukan lagi akan fashohahnya dan balaghahnya.

Pada masa awal pertumbuhannya, kajian al-balaghah lebih dititik beratkan pada kajian ilmu al-ma'ani, ini artinya bahwa ilmu al-ma'ani merupakan dasar Al-Balaghah, lebih lanjut ilmu al-ma'ani dan ilmu nahwu mempunyai kaitan yang sangat erat bahkan bisa disebut sebagai satu kesatuan karena keduanya sama-sama berfungsi menghilangkan lahn dan kesalahan berbahasa (Al-Mubarak, 1999:13).

Tammam Hasan (2000:279) membagi dua fase perkembangan albalaghah sebagai disipilin ilmu, yaitu: Perkembangan pertama lebih dekat kepada sisi kritik karya sastra (annaqd al-'amaly). Ke dua, lebih merekat kepada uslubiyat. Yang dimaksud dengan uslubiyat adalah cabang dari al-lisaniyat (linguistik) berperan terhadap analisa uslub. Uslub adalah pemilihan penggunaan salah satu cara yang memungkinkan untuk ta'bir yang bisa menjelaskan makna.

Di sini penulis akan membahas tentang al-balaghah yang meliputi pengertian al-balaghah, al-balaghah antara sebuah disiplin ilmu dan pengetahuan, dan sejarah perkembangan al-balaghah dari masa jahiliyah sampai masa Abbasiyah.

\section{Pengertian Al-Balaghah}

Kata al-balaghah merupakan pecahan kata atau derivasi dari بلغ yang mempunyai arti sampai dan berakhir, seperti pada contoh berikut: 


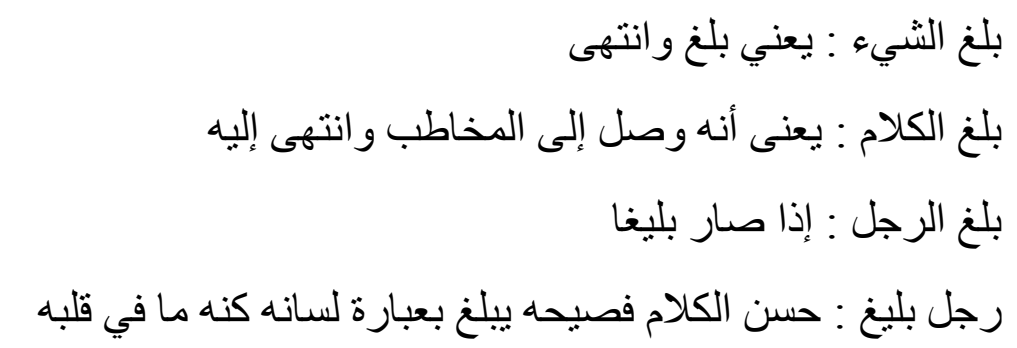

Orang Arab terdahulu menyamakan arti al-balaghah dengan alfashohah, kedua kata ini sering diartikan satu, sampai kira-kira abad IV seperti tercantum dalam kitan Shohhah al-Jauhari (393 H.) bahwa albalaghah adalah al-fashohah (Al-Mubarak, 1999:20).

Sedangkan menurut istilah al-balagah seperti yang diungkapkan Abdurrahman Habnakah Hasan (1996:129) adalah:

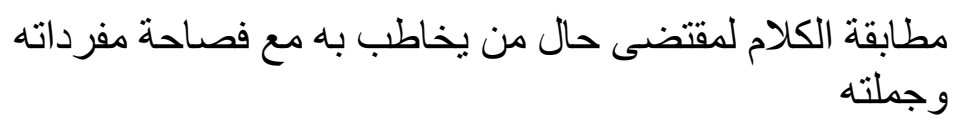

Artinya: "Kesesuaian kalam terhadap kondisi orang yang diajak berbicara disertai dengan fashahah (tepat) dalam susunan kata dan kalimatnya".

Sesuai dengan pengertiannya, maka al-balaghah tidak bisa dipisahkan dari bahasa, bahkan al-balaghah adalah perkara yang membantu bahasa untuk menunaikan tugas-tugasnya sebagai salah satu alat komunikasi (ta'bir) atau iblagh yang mencakup dua unsur bahasa yaitu makna dan lafaz (Al-Mubarak, 1999:19).

\section{Al-Balaghah sebagai Sebuah Disiplin Ilmu}

Al-Balaghah menjadi sebuah disiplin ilmu seperti yang dikenal pada zaman sekarang ini, melalui proses dan perjalanan yang sangat panjang. Tammam Hasan mengemukakan bahwa al-balaghah mengalami dua fase dalam perjalanannya antara sebagai sebuah pengetahuan dan 
sebagai sebuah disiplin ilmu. Beliau mengatakan: "Perkembangan albalaghah melalui dua tahap atau pase, Pertama: perkembangan yang lebih dekat kepada sisi kritik karya sastra (al-naqd al-'amaly). kedua: Lebih merekat kepada uslubiyyaat. Yang dimaksud dengan uslubiyyaat adalah cabang dari al-lisaniyat (studi bahasa modern) berperang terhadap analisa $u s l u b$. Uslub adalah pemilihan penggunaan salah satu cara yang memungkinkan untuk ta'bir ketika cara-cara ini bisa menjelaskan makna (Hasan, 2000:279).

Studi Al-Balaghah pertama kali dipelopori oleh para ilmuwan bahasa bukan oleh para ilmuwan nahwu. Al-Balaghah berkembang dari mulai sebuah batasan-batasan manthiqy, penjelasan-penjelasan falsafah, melalui proses yang panjang dan melelahkan, yang pada kahirnya menjadi sebuah disiplin ilmu yang kita lihat seperti sekarang ini. Pada awal terbentuknya sebagai disiplin ilmu, al-balaghah diungkapkan dengan bahasa yang kaku yang hanya menjelaskan tentang istilahistilah seperti layaknya pembahasan ilmu atau seperti dekat dengan ilmu mantiq, tetapi pada akhirnya juga menampilkan dzauq fithrah (cita rasa bahasa yang bisa dirasakan) dan emosi atau perilaku jiwa. Untuk lebih jelasnya bagaimana proses panjang tentang perkembangan $\mathrm{Al}$ Balaghah, berikut pembahasannya.

\section{Sejarah Perkembangan Al-Balaghah}

Syauqi Dhaef membagi sejarah perkembangan Al-Balaghah ke dalam 4 (empat) tahap, yaitu: 1) marhalah al-nasy'ah (pertumbuhan), 2) marhalah al-numuw (perkembangan), 3) marhalah al-izdihar (kejayaan), dan 4) marhalah al-dhubul (kemunduran) (Dhaif, 1999:5). Dalam pembahasan sejarah dan perkembangan Al-Balaghah, di sini penulis akan membahasnya mulai dari zaman jahiliyah, Islam, Umawi, dan Abbasi.

Pertama, Masa Jahiliyah dan Masa Permulaan Islam. Kehidupan orang Arab sebelum Islam mempunyai karakter yang erat berkaitan dengan bahasa dan keindahannya, kehidupan mereka yang selalu dilandasi atas dasar membanggakan keturunan, dudukan, bahasa, dan 
lain-lainya mempunyai efek terhadap bahasa, di mana disaat mereka membanggakan bahasanya, maka mereka berusaha dengan keras untuk mengungkapkan dengan fashahah dan balaghah yang tinggi, agar dapat dipandang dan dibanggakan.

Hal ini berarti bahwa orang Arab tidak hanya membanggakan begitu saja terhadap bahasanya, tetapi mereka juga berusaha agar yang mereka bangga-banggakan betul-betul berkualitas sehingga tidak dapat dikalahkan oleh yang lainnya. Kompetisi ini secara langsung berimbas pada keindahan bahasa dan fashohahnya, yang menunjukan bahwa mereka sudah mengenal Al-Balaghah al-kalam.

Dalam al-Qur'an sendiri ada beberapa ayat yang mengisyaratkan bahwa masyarakat Arab sudah mengenal al-balaghah dan perhatian mereka terhadap keindahan dalam berbahasa. Misalnya, keindahan kalimat dalam firman Allah SWT surah Ar-Rahman ayat 1-4 (Artinya: "(Tuhan) yang Maha pemurah, Yang Telah mengajarkan Al-Quran. Dia menciptakan manusia. Mengajarnya pandai berbicara") dan surah Al-Ahzab ayat 9 (Artinya: "Apabila ketakutan telah hilang, mereka mencaci kamu dengan lidah yang tajam...").

Selain ayat-ayat dari al-Quran, bukti lain yang menunjukan bahwa masyarakat Arab sudah mengenal dan menguasai al-balaghah adalah mu'jizat Rasul yang menantang mereka untuk membuat yang serupa dengan fashohah dan balaghoh al-Qur'an dengan gaya bahasanya yang sangat tinggi. Walaupun mereka tidak mampu, namun tantangan ini merupakan bukti bahwa mereka mempunyai kemampuan untuk membuat ibaraat dengan gaya bahasa dan fashahah yang tinggi.

Diriwayatkan bahwa Al-Walid bin Al-Mughirah salah seorang musuh bebuyutan Rasulullah saw mendengan ayat-ayat al-Qur'an yang dibacakan Rasulullah SAW, kemudian ia berkata:

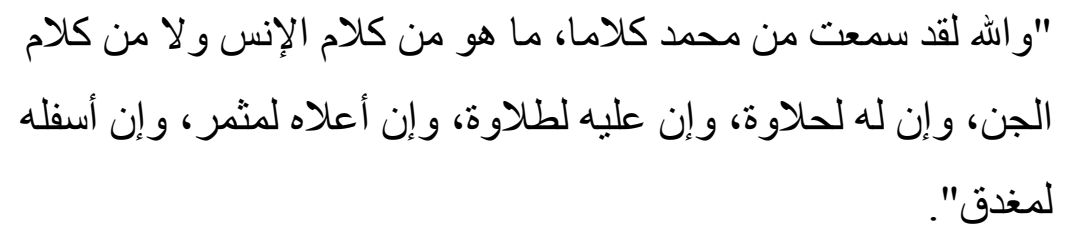


Artinya: "Demi Allah saya telah mendengar sebuah kalam (ayat al-Quran) dari Muhammad, ungkapannya bukanlah ungkapan manusia taupun jin, sesungguhnya ungkapan tersebut sangat bagus dan indah, permulaannya sangat berisi dan lebih lagi di penutupnya" (Dhaif, 1999:9).

Kekaguman al-Walid ini menunjukan bahwa masyarakat Arab telah mengenal akan fashohah dan balaghoh dalam sebuah ungkapan dan mempu untuk menilainya dengan objektif. Dalam sebuah Hadits diriwayatkan bahwa Rasulullah SAW bersabda:

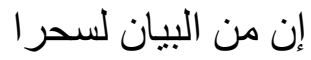

Di antara faktor yang mempunyai peran penting akan fashohah dan balighnya kalam masyarakat Arab adalah dzauq (cita rasa bahasa), karena dzauq mereka yang sangat tinggi itulah maka banyak sekali syair-syair yang lahir. Di samping itu, munculnya pasar-pasar seni ikut berperan membangkitkan dzauq bahasa ini, seperti: pasar Ukkadz juga kota Makkah yang digunakan sebagai tempat ajang perlombaan bacaan puisi atau prosa. Di samping berlomba dalam pembacaan karya syair mereka pun saling meminta pendapat tentang syair-syair yang mereka buat. Kita melihat aliran Zuhair bin Abi Salma, sebuah aliran syi'ir yang tidak asal saja dalam membuat syair sehingga al-Ashma'i berkata:

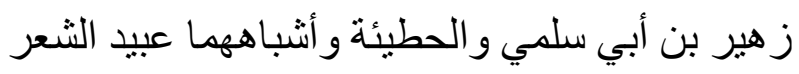

Artinya: "Zuhair bin Abi Salma, al-Huthaiah dan orang-orang yang seperti keduanya adalah hamba sya'ir" (Dhaif, 1999:12).

Al-Balaghah pada zaman Jahiliyah belum dikenal sebagai sebuah disiplin ilmu yang sudah matang dan mempunyai mustholahat yang terdefinisi dengan jelas. Dalam karya-karya mereka sangat banyak ditemukan akan balignya (indah dan tingginya) ungkapan mereka, 
secara teoritis Al-Balaghah belum dikenal, tetapi sudah dipraktekkan dan diterapkan dalam karya-karya mereka baik berupa syi'ir maupun natsr (Al-Mubarak, 1999:19).

Setelah Islam datang, maka perhatian masyarakat Arab akan fashohah dan balaghah semakin tumbuh dan berkembang, hal ini tidak lain karena al-Quran sebagai kitab suci umat Islam sangat indah dan dengan gaya bahasa yang membuat masyarakat Arab tercengan dan kagum akan keindahan gaya bahasanya. Selain al-Quran, hadis-hadis Nabi Muhammad SAW juga ikut berperan meningkatkan pertumbuhan dan perkembangan perhatian masyarakat Arab terhadap fashohah dan balaghah.

Al-Quran sebagai kitab suci umat Islam yang mempunyai gaya bahasa tinggi, selalu dibaca dan dilantunkan siang dan malam. Hal ini membuat masyarakat Arab semakin akrab dengan gaya bahasa alQuran yang indah dan tinggi. Bahkan al-Walid, salah satu musuh Islam, pernah berkata kepada kawan-kawannya:

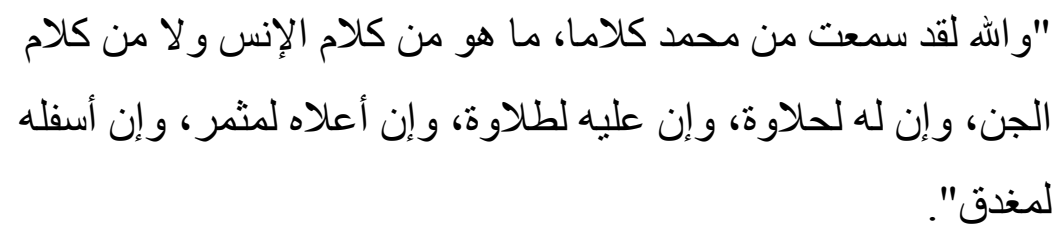

Sedangkan Rasulullah SAW melalui hadits-haditsnya yang juga mempunyai gaya bahasa yang indah dan penuh dengan fashohah dan balaghah selalui menghiasi perkataan beliau dalam memberikan bimbingan dan nasehat kepada para sahabatnya. Al-Jahidh (Dhaif, 1999:13) berkata:

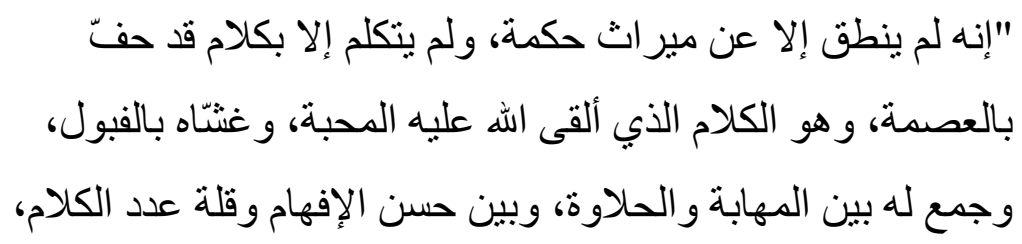




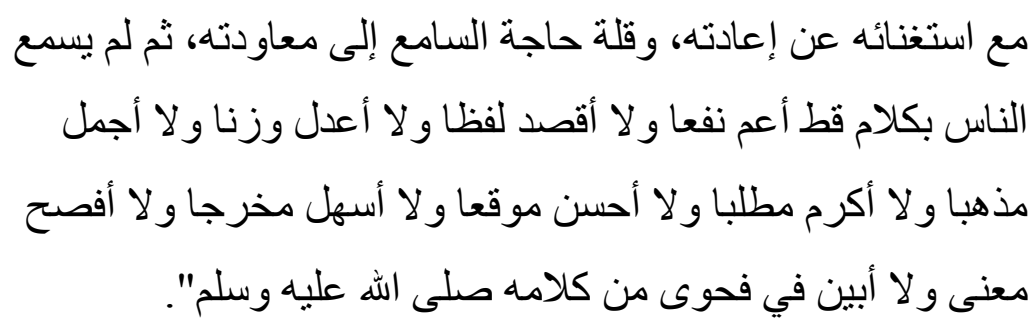

Demikianlah pertumbuhan Al-Balaghah pada masa jahiliyah dan masa permulaan Islam, masyarakat Arab sudah mengenal dan sudah mempraktekan fashohah dan balaghah meskipun secara teoritis mereka belum mengenalnya sebagai sebuah disiplin ilmu. Setelah Islam datang dengan kitab sucinya al-Quran dan dengan hadits Nabi Saw yang mempunyai gaya bahasa yang tinggi, membuat masyarakat Arab semakin punya perhatian yang lebih akan keindahan bahasa dan gaya bahasa yang tinggi, juga didukung oleh dzauq (cita rasa bahasa) mereka yang dalam.

Kedua, Masa Bani Umayyah. Pada masa Bani Umayyah, khitabah dengan berbagai macam jenisnya seperti khitabah politik, peringatan, pesta, nasehat dan lain-lainnya berkembang sangat pesat dan mengalami masa kemajuan yang signifikan. Banyak sekali para khatib yang terlahir dan terkenal-pada masa ini, seperti Ziyad dan al-Hajjaj sebagai khatib bidang politik, Sahban Wail sebagai khatib bidang mahafil (pesta/peringatan), Gaelan al-Dimsyiqi, Hasan al-bishri, dan Washil bin Atho sebagai khatib mauidhoh (nasehat).

Tidak hanya dalam bidang khitabah saja yang berkembang pada masa ini, akan tetapi puisi dan prosa pun mempunyai tempat yang besar dalam perkembangannya. Para utusan dari para penyair pun berdatangan untuk mengikuti perlombaan bait-bait puisi. Sehingga lahir pasar al-Mirbad di kota Bashrah dan pasar al-Kunasah di kota Kufah, sebagai tempat membaca puisi dan prosa. Kedua pasar puisi tersebut seperti pasar Ukadz pada masa jahiliyah.

Tumbuh dan berkembangnya khitabaat, asy'ar dan natsr mempunyai dampak yang poisitif terhadap perkembangan balaghah 
sebagai sebuah disiplin ilmu. Para khatib berusaha untuk mengungkapkan bahasa khitabahnya dengan gaya bahasa yang indah dan tinggi, banyak ditemukan komentar-komentar yang mengungkapkan akan fashohah dan balaghahnya para khatib pada masa ini, di antaranya seperti yang diungkapkan Al-Sya'bi mengomentari Ziyad (Dhaif, 1999:14):

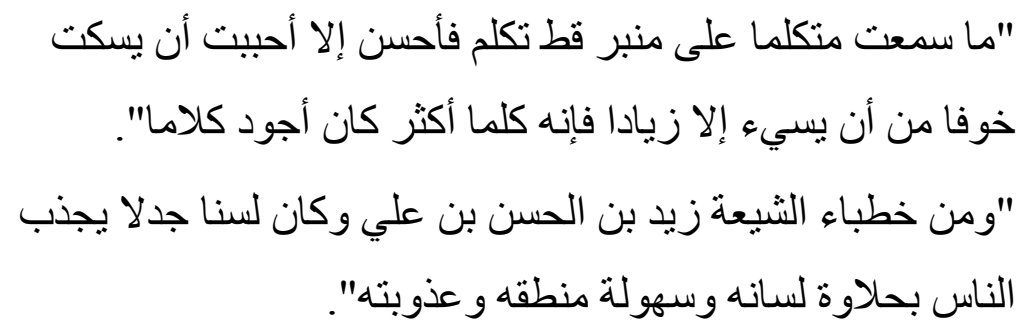

Banyaknya aliran dan madhab yang lahir dan tumbuh pada masa ini mempunyai peran dan dampak yang positif terhadap berkembangnya Al-Balaghah, hal ini dikarenakan seringnya terjadi tukar pikiran, perdebatan, dan diskusi tentang politik, teologi dan keagamaan antar sesama penganut madhab atau dengan lainya. Di antara madhab yang lahir pada masa ini adalah khawarij, syi'ah, zubaeriyyun, Umawiyyun, murji'ah, jabariyah, qodariyah dan mu'tazilah (Dhaif, 1999:15). Terjadinya diskusi dan perdebatan ini membuat pola pikir dan wawasan mereka semakin luas sehingga pandangan dan pola pikir mereka terhadap balaghah juga semakin meningkat.

Selain itu, pada masa ini masyarakat banyak yang bertempat tinggal dan menetap di perkotaan, yang tentunya mempunyai pola pikir yang berbeda dengan masyarakat di pedasaan.

Perkembangan syi'ir lebih dominan pada masa ini dibanding khitabah, hal ini dikarenakan banyaknya muncul aliran dan panatisme sehingga bermunculan syi'ir yang memuji kelompoknya dan syi'ir yang mencela lawannya. Juga dukungan dari para penguasa untuk 
menyelenggarakan lomba baca puisi dengan penghargaan yang memuaskan.

Berangkat dari itu semua, maka mulailah terbentuk dasar-dasar kaidah balaghah yang sejak awal (masa Jahiliyah dan permulaan Islam) sudah nampak kecintaan dan perhataian masyarakat Arab terhadap alfashohah dan Al-Balaghah seperti yang telah dijelaskan di atas.

Ketiga, Masa Bani Abbasiyah. Pada masa Bani Abbasiyah perkembangan al-balaghah tidak kalah pesatnya pada masa Bani Umayyah. Perkembangan sastra tidak hanya pada karya sastra puisi saja akan tetapi puisi dan prosa. Ada beberapa sebab kemajuan yang diungkapkan oleh Syauqi Dhaif, pertama kemajuan ini seiring dengan perkembangan kehidupan logika dan peradaban masyarakat pada saat itu, kedua munculnya dua kelompok mu'allim (pengajar), kelompok pertama berkonsentrasi pada bahasa dan puisi sedangkan kelompok kedua berkonsentrasi pada pidato, debat, pembuatan hokum dalil dan pendalaman ta'bir (Dhaif, 1999:19).

Perkembangan prosa pada era ini ditunjukkan dengan munculnya prosa ilmiyah, penguasaan karya-karya asing yang dialih bahasakan berupa sastra, politik, pilsafat. Salah satunya adalah Ibnul Muqaffa' (143 H) menterjemahkan dari Bahas Persia buku-buku sejarah yang beragam, buku-buku sastra dan politik, kalilah wa dimnah, dan sebagian besar mantiqnya Aristoteles.

Disamping itu pula Ibnul Muqaffa' meletakkan uslub yang baru dalam ilmu Balaghah yang dikenal dengan uslub al-muwallad, yaitu satu uslub yang memperhatikan ketelitian dalam pemilihan lafadz-lafadz dan meletakkannya pada tempat-tempat yang betul sehingga memunculkan makna-makna baru tanpa ada cacat atau keraguan. Yang pertama ia titik tekankan dalam balaghah ini adalah bagian logika.

Pada masa ini al-balaghah sebagai ilmu pengetahuan sudah terbentuk dengan baik, sehingga mustholahaat tentang pembahasan albalaghah sudah terdefinisi dan tertata dengan baik, para ulama mempunyai peran terhadap terbentuknya mushtolahaat ini, seperti al- 
Ashmui ulama yang mempunyai ide tentang al-iltifaat, al-muthabaqah, althibaq, dan al-jinass dalam kajian al-balaghah (Dhaif, 1999:30).

\section{Penutup}

Al-Balaghah sebagai sebuah disiplin ilmu mempunyai sejarah dan perkembangan yang panjang di dunia Islam. Pada jaman Jahiliyah albalaghah secara teoritis belum dikenal oleh masyarakat Arab, akan tetapi pada prakteknya mereka sudah menggunakannya dalam karya mereka baik berupa syi'ir maupun natsr, demikian juga pada masa permulaan Islam. Dengan dukungan al-Quran sebagai kitab suci umat Islam yang mempunyai gaya bahasa yang sangat tinggi dan Hadits Nabi Saw, juga didukung oleh pola pikir dan wawasan masyarakat Arab yang semakin baik, al-balaghah mengalami kemajuan yang sangat signifikan sampai banyak karya yang bermunculan. $\square$

\section{DAFTAR PUSTAKA}

Ahmad Al-Hasyimi. 1978. Jawahir Al-Balaghah fii Al-Ma'ani wa Al-Bayan wa Al-Badi'. Baerut: Dar El-Fikr.

Al-Mubarak, Mazin. 1999. Al-Mujaz fii Tarikh Al-Balaghah. Bairut: Darul Fikr al-Mu'ashir, Damaskus: Dar El-Fikr.

Bakri, Syekh Amin. 1982. Al-Balaghah Al-Arabiyah fii Tsaubiha Al-Jadid Ilm Al-Bayan. Baerut: Darl al-Tsaqafah al-Arabiyah.

Dhaif, Syauqi. 1999. Al-Balaghah Tathawwur wa Tarikh. Kairo: Darul Ma'arif. 
Hasan, Abdurrahman Hanbakah. 1996. Al-Balaghah Al-'Arabiyah Ususuhaa wa 'Ulumuhaa wa Fununuhaa. Damaskus: Dar Al-Qalam.

Hasan, Tammam. 2000. Al-Ushul Dirasah efistimulujiyyah li Al-Fikr AlLughawy 'inda Al-'Arab -Al-Nahwu - Figh Al-Lughah - Al-Balaghah. Kairo: 'Alam Al-Kutub. 